\title{
Dopaminergic Input to the Inferior Colliculus in Mice
}

\author{
Alexander A. Nevue ${ }^{1}$, Cameron J. Elde ${ }^{1}$, David J. Perkel ${ }^{2,3,4}$ and Christine V. Portfors ${ }^{1 *}$ \\ ${ }^{1}$ School of Biological Sciences, Washington State University Vancouver, Vancouver, WA, USA, ${ }^{2}$ Department of Biology, \\ University of Washington, Seattle, WA, USA, ${ }^{3}$ Department of Otolaryngology - Head and Neck Surgery, University of \\ Washington, Seattle, WA, USA, ${ }^{4}$ The Virginia Merrill Bloedel Hearing Research Center, University of Washington, Seattle, \\ WA, USA
}

The response of sensory neurons to stimuli can be modulated by a variety of factors including attention, emotion, behavioral context, and disorders involving neuromodulatory systems. For example, patients with Parkinson's disease (PD) have disordered speech processing, suggesting that dopamine alters normal representation of these salient sounds. Understanding the mechanisms by which dopamine modulates auditory processing is thus an important goal. The principal auditory midbrain nucleus, the inferior colliculus (IC), is a likely location for dopaminergic modulation of auditory processing because it contains dopamine receptors and nerve terminals immunoreactive for tyrosine hydroxylase (TH), the rate-limiting enzyme in dopamine synthesis. However, the sources of dopaminergic input to the IC are unknown. In this study, we iontophoretically injected a retrograde tracer into the IC of mice and then stained the tissue for $\mathrm{TH}$. We also immunostained for dopamine beta-hydroxylase (DBH), an enzyme critical for the conversion of dopamine to norepinephrine, to differentiate between dopaminergic and noradrenergic inputs. Retrogradely labeled neurons that were positive for TH were seen bilaterally, with strong ipsilateral dominance, in the subparafascicular thalamic nucleus (SPF). All retrogradely labeled neurons that we observed in other brain regions were TH-negative. Projections from the SPF were confirmed using an anterograde tracer, revealing $\mathrm{TH}$-positive and $\mathrm{DBH}$-negative anterogradely labeled fibers and terminals in the $\mathrm{IC}$. While the functional role of this dopaminergic input to the $\mathrm{IC}$ is not yet known, it provides a potential mechanism for context dependent modulation of auditory processing.

Keywords: subparafascicular thalamic nucleus, tyrosine hydroxylase, auditory midbrain, catecholamines, tract tracing

\section{INTRODUCTION}

Dopamine plays many roles in the brain, in such processes as movement, attention, reward, and motivation, and in disorders including Parkinson's disease (PD), schizophrenia, and addiction (Maia and Frank, 2011). Less well understood is a role for dopamine in sensory processing, though there is mounting evidence that dopamine is involved in auditory processing. For example, people with $\mathrm{PD}$, a neurological disease caused by degeneration of the dopaminergic system, have difficulties processing speech, including deficits estimating the time intervals of an acoustic speech signal (Gräber et al., 2002), altered emotional prosody (Schröder et al., 2010), and difficulty perceiving the individual's own loudness (Kwan and Whitehill, 2011). Dopamine modulates 
auditory responses to vocalizations in songbirds (Leblois et al., 2010) and is present in auditory circuitry in fish (Forlano et al., 2014). In addition, neural responses in the principal auditory midbrain nucleus, the inferior colliculus (IC), can be altered by a reward-based stimulus (Metzger et al., 2006) and by the application of exogenous dopamine (Gittelman et al., 2013). Although it is clear that dopamine modulates auditory processing in the forebrain and midbrain, the source(s) of dopaminergic input to auditory regions are not known.

In this study, we examined the sources of dopaminergic input to the IC. We focused on the IC because it is an obligatory station in the ascending auditory pathway, contains dopaminergic fibers and terminals (Paloff and Usunoff, 2000; Tong et al., 2005), and expresses D2-like dopamine receptors (Wamsley et al., 1989; Weiner et al., 1991; Hurd et al., 2001; Satake et al., 2012). While the majority of dopaminergic neuron somata are located in the substantia nigra and ventral tegmental area, there are many groups of dopaminergic neurons in the central nervous system. One potential candidate for dopaminergic innervation of the IC is the subparafascicular thalamic nucleus (SPF). The SPF is split into two subdivisions, the magnocellular (SPFm) and parvicellular (SPFp; Paxinos and Franklin, 2001) and is part of the A11 dopaminergic cell group (Takada et al., 1988). While the SPF is known to project to the IC (Yasui et al., 1992), it is not known whether these neuronal projections are dopaminergic. Dopaminergic targets of the SPF that have been identified to date include the neocortex, spinal cord, olfactory tubercle, and amygdala (Takada et al., 1988; Takada, 1993) but not the IC (Moriizumi and Hattori, 1992).

The goal of this study was to determine the sources of dopaminergic input to the IC by placing a retrograde tracer into the IC of mice and immunostaining for tyrosine hydroxylase (TH). We found the SPF to be the region where retrogradely labeled neurons were dopaminergic. Anterograde tracer injected in the SPF labeled TH-positive terminals in the IC, indicating that the SPF provides the dopaminergic input to the IC. Determining the source of dopaminergic projections into the auditory system is an important first step in understanding the effects and underlying cellular and synaptic actions of dopamine on auditory processing.

\section{MATERIALS AND METHODS}

\section{Animals}

We used normal hearing $\mathrm{CBA} / \mathrm{CaJ}$ and $\mathrm{C} 57 \mathrm{BL} / 6$ adult mice ( 5 males, 8 females) obtained from Jackson Laboratory or bred in our colony for the retrograde $(n=9)$ and anterograde $(n=4)$ tracer experiments. All animals had free access to food and water and were housed on a reversed $12 \mathrm{~h} \mathrm{light} / 12 \mathrm{~h}$ dark schedule. All care and procedures were in accordance with the guidelines of the National Institutes of Health and were approved by the Washington State University Institutional Animal Care and Use Committee.

\section{Preparation of Animals for Tracer Injections}

We iontophoretically injected the tracers into the regions of interest in awake animals. To prepare the animals for the tracer injections, they were anesthetized for mounting of a headpost onto the skull using surgical techniques we have previously described (Muniak et al., 2012). Once the headpost was mounted, we made a craniotomy (about $1 \mathrm{~mm} \times$ $1 \mathrm{~mm}$ ) above the desired brain region based on stereotaxic coordinates (Paxinos and Franklin, 2001). We then covered the hole with petroleum jelly and/or bone wax to prevent the brain from dehydrating, applied lidocaine and an antibiotic (Neosporin) to the exposed muscle, and returned the mouse to its home cage to recover from the surgery for at least 1 day before a tracer deposit was made. On the experimental day, the animal was placed in a sound attenuating chamber with its headpost bolted into a custom stereotaxic apparatus. The animal was given a low dose $(<5 \mathrm{mg} / \mathrm{kg}$, i.p.) of acepromazine to ease any stress of putting the animal in the restraint.

\section{Iontophoretic Tracer Injections}

For retrograde tracing, we used a $2-4 \%$ solution of Fluorogold (FG; Fluorochrome) in a sodium acetate buffer in nine animals. In two animals, we injected both FG and $1 \%$ cholera toxin subunit B (CTB; List Biological Laboratories) dissolved in distilled water into the IC. We used glass micropipettes (resistance 3-5 M $\Omega$ ) filled with the FG or CTB to record electrophysiological response properties prior to depositing the tracer. Recording electrodes were advanced into the left IC by a hydraulic micropositioner (David Kopf Instruments) driven from outside the sound attenuating chamber. We used standard methods in our laboratory to record extracellular electrical activity in response to auditory stimuli (Gittelman et al., 2013). We deposited the tracers once we were confident that the tip of the electrode was in the IC based on frequency responses of the multiunit clusters (Portfors et al., 2011). The FG and CTB were deposited by injecting $5 \mu \mathrm{A}$ of current for $8 \mathrm{~min}$ ( $7 \mathrm{~s}$ on/7 $\mathrm{s}$ off). The animal was then returned to its home cage for 7 days survival time.

In four mice, we deposited 10\% 10,000 MW biotinylated dextran amine (BDA; Life Technologies) dissolved in $0.9 \%$ saline into the SPF. We located the SPF using stereotaxic coordinates (1.3-1.6 $\mathrm{mm}$ caudally from bregma and $0.1-0.5 \mathrm{~mm}$ lateral to the midline; Paxinos and Franklin, 2001). The BDA was deposited by injecting $5 \mu \mathrm{A}$ of current for $10 \mathrm{~min}$ (7 s on/7 s off). The animal was then returned to its home cage for 7 days survival time.

\section{Perfusion and Tissue Collection}

The mice were deeply anesthetized with isoflurane in an induction chamber. We then transcardially perfused each mouse using $60 \mathrm{~mL}$ of buffered $10 \%$ formalin or $4 \%$ paraformaldehyde in $0.1 \mathrm{M}$ phosphate buffer solution (PBS, $\mathrm{pH}$ 7.4). The brain was removed and cryoprotected overnight in $20 \%$ sucrose solution in $0.1 \mathrm{M}$ PBS. We sectioned the brain coronally at a thickness of $50 \mu \mathrm{m}$ starting just caudal to the dorsal 
cochlear nucleus and ending rostral to the SPF using a Leica SM2000 R freezing microtome (Leica Biosystems). Sections were collected serially in $0.1 \mathrm{M}$ PBS and stored at $4^{\circ} \mathrm{C}$ until use.

\section{Immunohistochemistry; TH, DBH, and Streptavidin}

Sections were rinsed $10 \times$ in $0.1 \mathrm{M}$ PBS, then gently shaken while incubated overnight in a solution of rabbit anti-TH polyclonal primary antibody (1:1500, Millipore), 3\% normal donkey serum (Millipore), and $0.4 \%$ Triton X-100 (SigmaAldrich) in $0.1 \mathrm{M}$ PBS. The polyclonal primary antibody for dopamine beta-hydroxylase $(\mathrm{DBH})$ made in a rabbit (1:4000, ImmunoStar) was used for differentiating dopaminergic and noradrenergic inputs. Sections were rinsed $10 \times$ in $0.1 \mathrm{M}$ PBS. TH and DBH labeled cells and fibers were visualized by incubating the sections in fluorescently tagged secondary antibodies for $2 \mathrm{~h}$. The secondary antibody used for labeling $\mathrm{TH}$ and $\mathrm{DBH}$ primary antibodies was either an Alexa Fluor 488 or 568 conjugated to donkey anti-rabbit IgG (1:250, Life Technologies). For confocal microscopy, we used an antibody to FG (1:800, Millipore) with an Alexa Fluor 568 secondary (1:250, Life Technologies) and a sheep anti-TH polyclonal antibody (1:1500, Millipore) with an Alexa Fluor 488 secondary (1:250, Life Technologies). To visualize the CTB we used a goat antiCTB primary antibody (1:10,000, List Biological Laboratories) with an Alexa Fluor 568 conjugated anti-goat secondary antibody (1:250, Life Technologies). For the anterograde experiments, we used Alexa Fluor 488 conjugated streptavidin (1:250, Life Technologies) to visualize the tracer. The sections were mounted on Superfrost Plus microscope slides (Fisher Scientific), dehydrated and cleared, and coverslipped with DPX (Electron Microscopy Sciences). Label was observed using a Leica TCS SP8 confocal microscope (Leica Microsystems). The location of labeled cell bodies and terminals were identified using a Nissl stain on the adjacent series of sections.

\section{Antibody Characterization}

The specificity of the TH antibody was validated by labeled cells in known dopaminergic areas such as the substantia nigra (Hokfelt et al., 1976), as well as the characteristic shape of the SPFm, defined by the TH-positive cells (Yasui et al., 1992). The specificity of the $\mathrm{DBH}$ antibody was shown by the presence of DBH-positive neurons in the locus coeruleus (Benarroch, 2009). Additionally, areas of the brain, including the SPF, that are known to contain dopaminergic and not noradrenergic cell bodies showed positive immunofluorescence for the $\mathrm{TH}$ antibody but not the DBH antibody (Takada et al., 1988). Antibodies used in these experiments are given in Table $\mathbf{1}$.

\section{Data Analysis}

For analysis of double labeling, we examined every other $50 \mu \mathrm{m}$ section in the SPFm. Approximately four sections were counted for each animal. Cells were counted with live images. In each section, we counted the number of retrogradely labeled cells and the number of retrogradely labeled cells that were TH positive on the ipsilateral and contralateral sides. We used Student's $t$-tests to determine statistical significance between groups. Data are presented as mean $\pm S D$. For subjective analysis of labeled fiber density, an observer assigned a score of $0-3$ to fiber density while examining the label in the microscope. A score of 0 represented no fibers or terminals and a score of 3 represented extremely dense terminal labeling.

\section{RESULTS}

To determine the sources of dopaminergic input to the IC, we iontophoretically injected FG or CTB into the left IC in nine mice. In two mice, deposits of both FG and CTB were made. The location of each deposit was confirmed after tissue processing (Figure 1). In all of these animals, the tracer did not spread into neighboring regions such as the superior colliculus or periaqueductal gray. Some of the lateral deposits had a small diffusion into the cerebellum but these deposits were still used for quantification because we did not observe any anterogradely labeled fibers from the SPF in the cerebellum. By staining the same sections for $\mathrm{TH}$ and $\mathrm{DBH}$, we identified which of the retrogradely labeled cell bodies were dopaminergic.

Retrogradely labeled cell bodies were found in all the expected auditory nuclei including the dorsal cochlear nucleus, ventral cochlear nucleus, contralateral IC, superior olivary complex, nuclei of the lateral lemniscus, and auditory cortex (Adams, 1979; Brunso-Bechtold et al., 1981; Saldaña et al., 1996; Frisina et al., 1998; Winer et al., 1998). However, none of those labeled cells were $\mathrm{TH}$-positive. Cell bodies containing both FG and TH immunoreactivity, but not DBH

TABLE 1 | List of antibodies used in this study.

\begin{tabular}{lllcll}
\hline Level & Antigen & Host & Conjugated & Dilution & Source \\
\hline Primary & TH & Rabbit & - & $1: 1500$ & Millipore AB152 \\
Primary & TH & Sheep & - & $1: 1500$ & Millipore AB1542 \\
Primary & RBH & Rabbit & - & $1: 4000$ & ImmunoStar 22806 \\
Primary & Rabbit & Goat & - & $1: 800$ & Millipore AB153-I \\
Primary & CTB & Donkey & Alexa 488 & $1: 10,000$ & List Biological \#703 \\
Secondary & Anti-rabbit & Donkey & Alexa 568 & $1: 250$ & Life Technologies A-21206 \\
Secondary & Anti-rabbit & Alexa 488 & $1: 250$ & Life Technologies A-10042 \\
Secondary & Anti-sheep & Donkey & Alexa 568 & $1: 250$ & Life Technologies A-11015 \\
Secondary & Anti-goat & Donkey & & Life Technologies A-11057
\end{tabular}




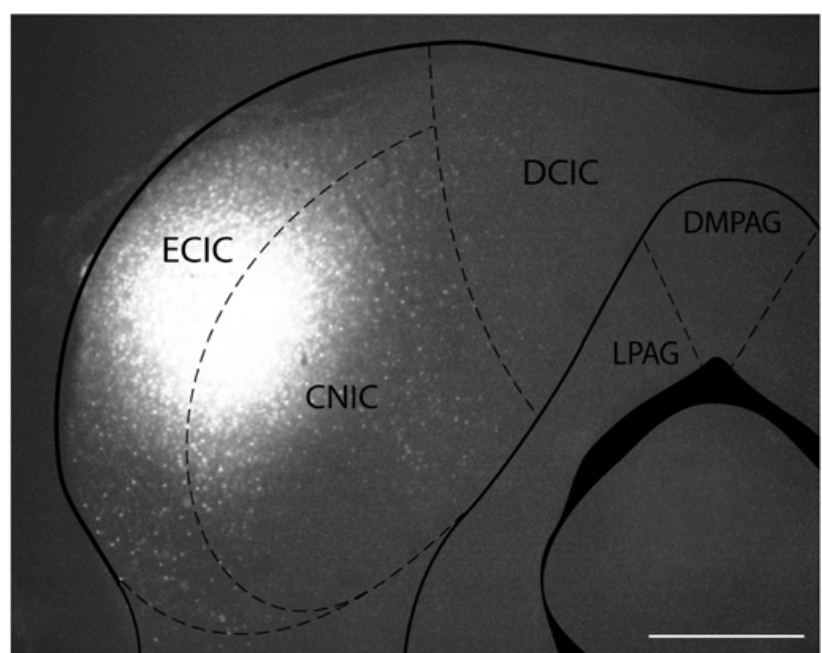

FIGURE 1 | lontophoretic injections of Fluorogold (FG) and cholera toxin subunit B (CTB) were made in the left inferior colliculus (IC). These injections were guided by electrophysiological response properties in awake animals. All deposits were confirmed to be in the IC. Example deposit site overlaid on a schematic coronal section of the IC (modified from Paxinos and Franklin, 2001) to delineate the boundaries of the IC. Atlas used with permission from Paxinos and Franklin (2001). Abbreviations: CNIC, central nucleus of the IC; ECIC, external cortex of the IC; DCIC, dorsal cortex of the IC. DMPAG and LPAG, periaqueductal gray. Scale bar $250 \mu \mathrm{m}$.

immunoreactivity, were found only in the SPF. Few retrogradely labeled and $\mathrm{TH}$-positive cells were found in the rostral part of the SPFp. Strong double labeling was seen in the SPFm (Figure 2).

There were more retrogradely labeled cells in the ipsilateral SPF than in the contralateral SPF (ipsilateral, $49.1 \pm$ 26.3; contralateral, $5.4 \pm 2.6$; Figure 3A). Although the ipsilateral side had a significantly higher number of doubly labeled cells than the contralateral side (ipsilateral, $41.9 \pm$ 24.0; contralateral, $1.6 \pm 2.0 ; p<0.001)$, the percentage of retrogradely labeled cells that were $\mathrm{TH}$-positive was not significantly different between the ipsilateral and the contralateral side $(85.4 \pm 5.6 \%$ vs. $78.73 \pm 16.3 \% ; p=0.212$; Figure 3B).

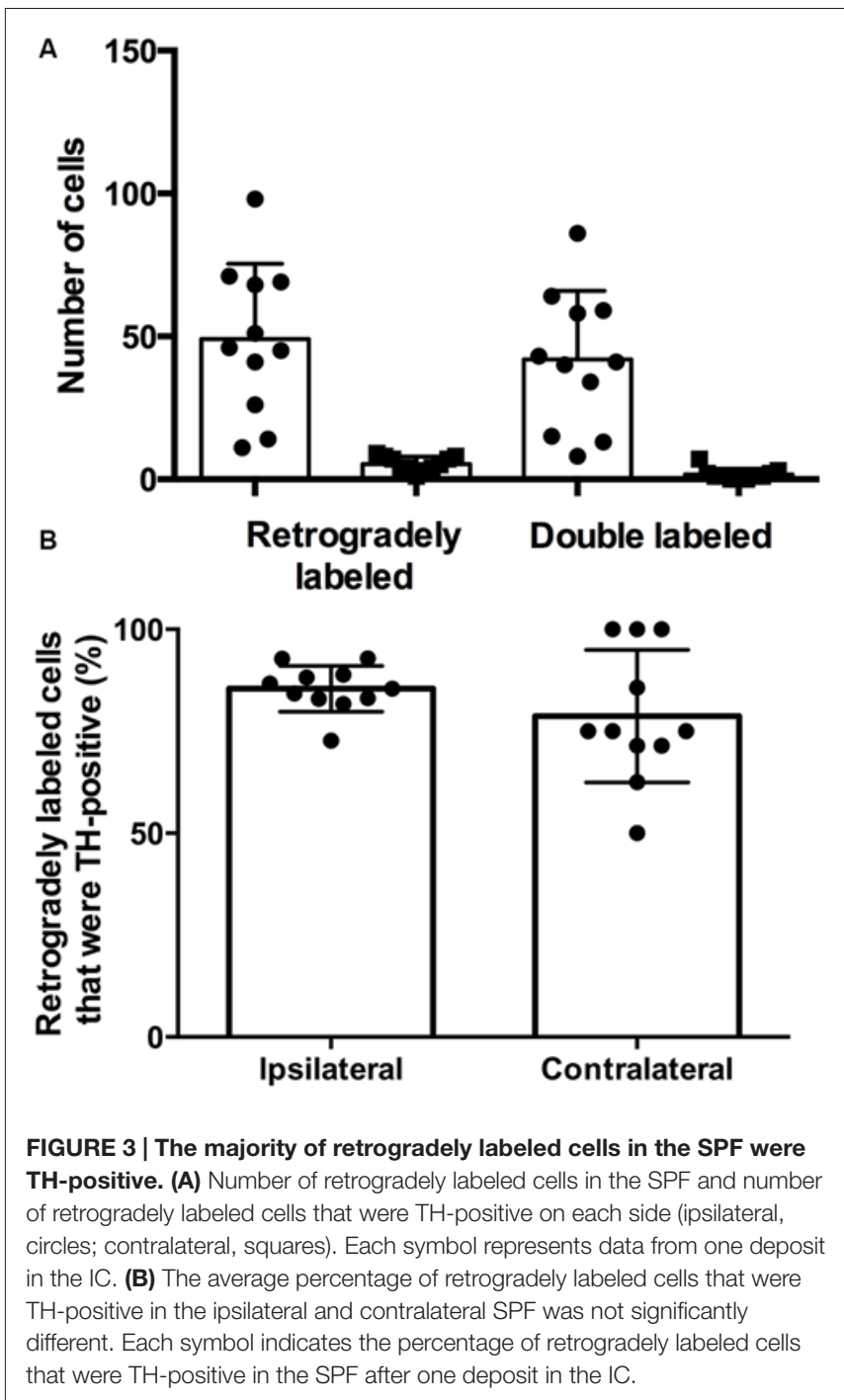

To confirm that the SPF sends dopaminergic projections to the $\mathrm{IC}$, we injected $10 \mathrm{~K} \mathrm{BDA}$, an anterograde tracer, into the SPF in four mice (Figure 4A). We found anterogradely labeled fibers that were $\mathrm{TH}$-positive in both the ipsilateral and
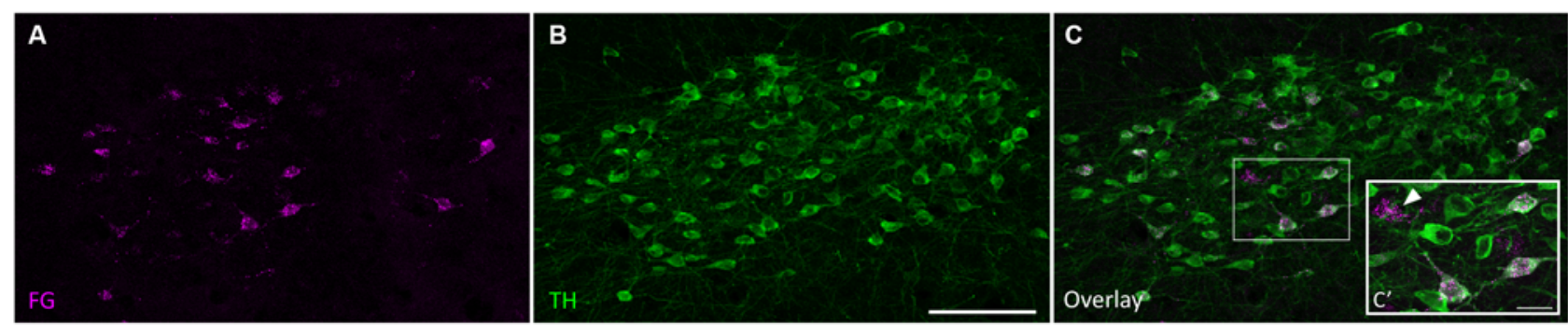

FIGURE 2 | Tyrosine hydroxylase (TH)-positive cells in the SPF project to the IC. (A) Retrogradely labeled cells in the SPF after a FG deposit in the IC. (B) TH-positive neurons in the SPF. (C) Overlay of images showing TH immunoreactivity in retrogradely labeled cells. (C') Inset shows retrogradely labeled neurons stained with TH (magenta+green yields white overlay), and retrogradely labeled TH-negative neurons (marked with an arrow). In this section, 25 cells were retrogradely labeled, 22 of which were TH-positive. Scale bar: (B) $100 \mu \mathrm{m}$; (C') $20 \mu \mathrm{m}$. 


\section{A}

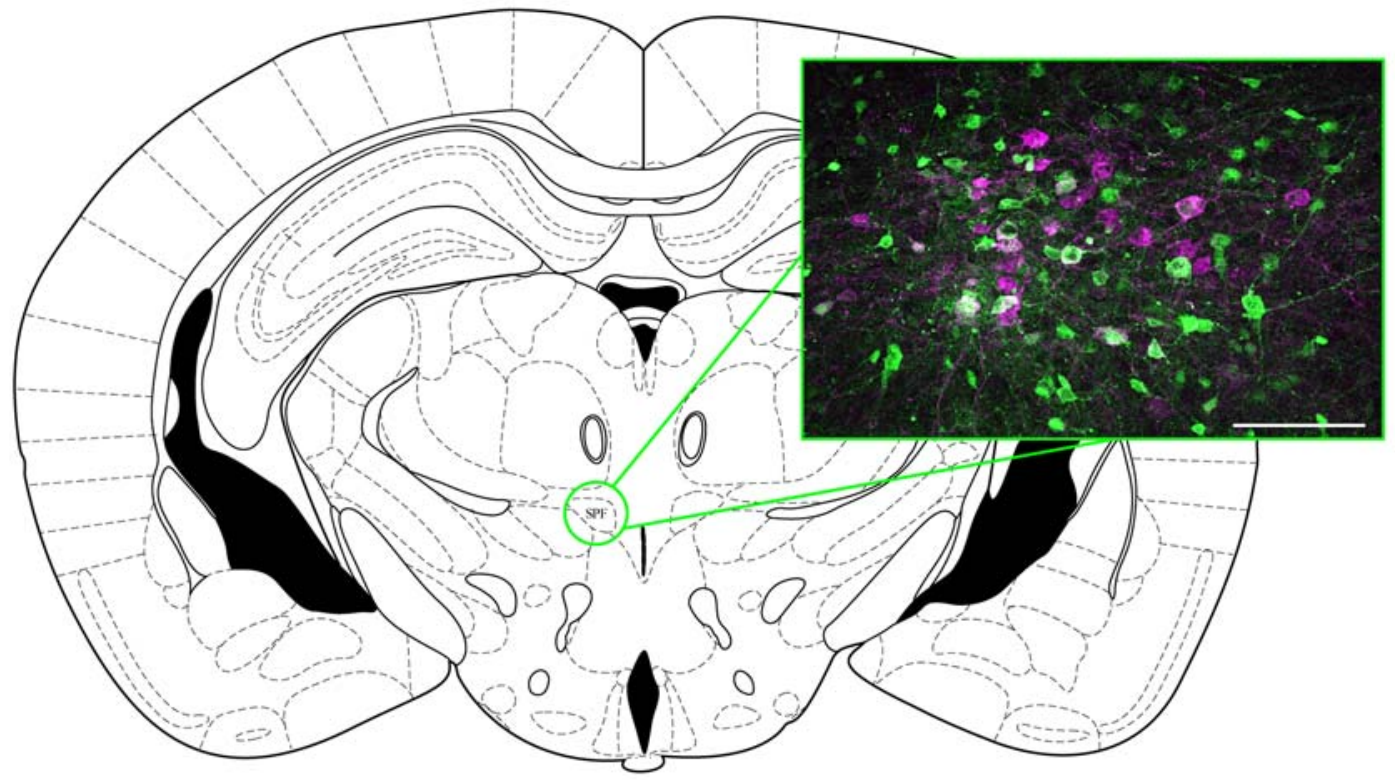

B

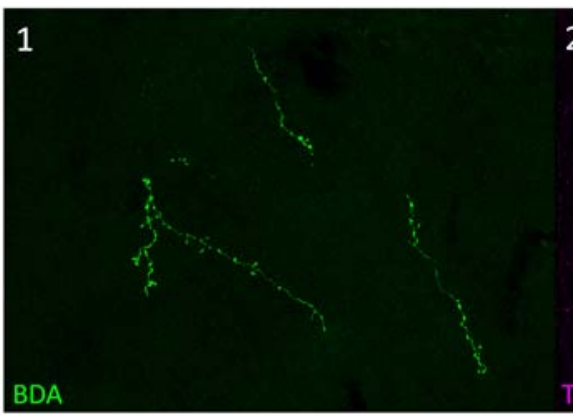

2

3

C

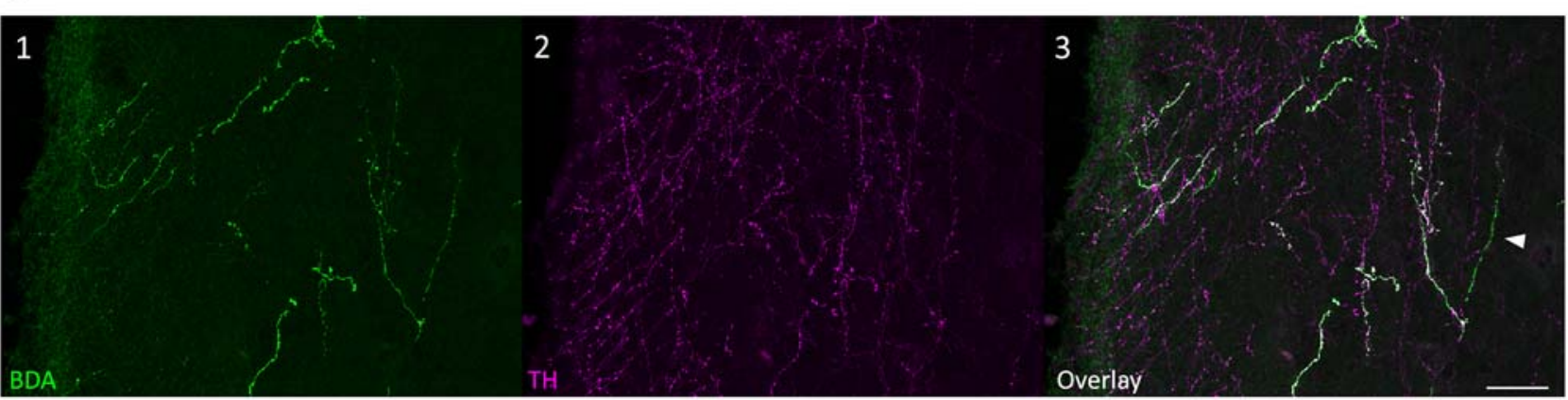

FIGURE 4 | Anterograde tracing confirmed that projections from SPF to IC were TH-positive. (A) Coronal section showing the SPF and an example biotinylated dextran amine (BDA) deposit located within the SPF. The magenta cells were TH-positive; green cells were labeled with BDA. (B) Anterogradely labeled fibers from the SPF were colocalized with TH in the CNIC. (B1) Anterogradely labeled fibers and terminals in the CNIC, ipsilateral to the deposit site. (B2) TH-positive fibers and terminals in the ipsilateral CNIC. (B3) Overlay of images showing that some anterogradely labeled fibers were TH-positive (white) in the ipsilateral CNIC. The arrow denotes an anterogradely labeled fiber that was TH-negative. (C) Anterogradely labeled fibers from the SPF were colocalized with TH in the ECIC. (C1) Anterogradely labeled fibers and terminals in the ECIC, ipsilateral to the deposit site. (C2) TH-positive fibers and terminals in the ipsilateral ECIC. (C3) Overlay of images showing that some anterogradely labeled fibers were TH-positive (white) in the ipsilateral ECIC. The arrow denotes an anterogradely labeled fiber that was TH-negative. Atlas used with permission from Paxinos and Franklin (2001). Scale bar: (A) $100 \mu \mathrm{m} ;$ (B,C) $25 \mu \mathrm{m}$.

contralateral IC. Additionally, there were anterogradely labeled fibers in the IC that were TH-negative, which is in agreement with the results of our retrograde tracing. Anterogradely labeled fibers that were both $\mathrm{TH}$-positive and $\mathrm{TH}$-negative were found in the central nucleus (Figure 4B), and external and dorsal cortices of the IC (Figure 4C). Qualitatively, there were more anterogradely labeled fibers from the SPF that were $\mathrm{TH}$ positive in the external and dorsal cortices of the IC than in the central 
TABLE 2 | Qualitative distribution of TH-positive fibers in the inferior colliculus (IC).

\begin{tabular}{lcc} 
Subdivision of IC & Density of TH fibers & Density of TH + BDA fibers \\
\hline CNIC & ++ & + \\
ECIC & +++ & ++ \\
DCIC & +++ & ++ \\
\hline
\end{tabular}

Note: + indicates low density and +++ indicates high density.

nucleus (Table 2). An important future study will be to determine the topography of the projections from SPF to IC and determine the spatial distribution in subdivisions of the IC. Anterogradely labeled fibers in the IC were DBH-negative (Figure 5). Although DBH immunoreactivity has not been detected in SPF somata, it is possible that their terminals in IC do express DBH and could synthesize norepinephrine. We tested this possibility, and did not find $\mathrm{DBH}$ immunoreactivity in SPF-derived terminals within the IC, confirming that the $\mathrm{TH}$-positive fibers were dopaminergic but not noradrenergic. There were $\mathrm{TH}$-positive fibers in the IC that were not labeled with BDA. These could be unlabeled afferent fibers from SPF, or they could represent noradrenergic fibers from the locus coeruleus (Klepper and Herbert, 1991; Hormigo et al., 2012). No TH-positive cell bodies were observed in the IC (Jaeger and Joh, 1983; Kitahama et al., 1996).

Finally, we found that all other retrogradely labeled cells were $\mathrm{TH}$-negative, including those in known dopaminergic areas such as the substantia nigra (Figure 6). As expected, noradrenergic cells in the locus coeruleus were retrogradely labeled (Klepper and Herbert, 1991; Hormigo et al., 2012).

\section{DISCUSSION}

Although the IC contains dopamine receptors (Wamsley et al., 1989; Weiner et al., 1991), has TH-positive fibers (this study; Tong et al., 2005), and shows altered neuronal response properties when exogenous dopamine is applied (Gittelman et al., 2013), the source of the dopaminergic innervation in the IC has not yet been identified. In this study, we combined retrograde tract tracing with immunostaining for $\mathrm{TH}$ and found that the SPF is the major source of dopaminergic input to the IC of mice. Knowing the source of the dopaminergic input to the IC is the first step in determining the behavioral contexts that elicit dopamine release in the IC, and will facilitate future studies to tease apart the neuromodulatory circuits involved in the encoding of salient auditory stimuli.

Prior to this study, it was not known that dopaminergic neurons in the SPF project to the auditory system. We found that approximately $80 \%$ of the retrogradely labeled cells in the SPF were $\mathrm{TH}$-positive and $\mathrm{DBH}$-negative. Moreover, our anterograde tracer deposits in the SPF resulted in labeled fibers and terminals in the IC that were also $\mathrm{TH}$-positive and $\mathrm{DBH}$-negative, confirming that dopaminergic cells in the SPF project to the IC. The SPF is known to project to the IC, but the cells that project to the IC were previously thought not to be the dopaminergic cell population (Moriizumi and Hattori, 1992). The SPF is known to contain dopaminergic neurons, is part of the A11 dopaminergic cell group (Takada et al., 1988), and sends dopaminergic projections to the spinal cord (Takada, 1993). Animal studies have suggested that these projections are involved in locomotion, pain control, migraines, and restless legs syndrome (Blessing and Chalmers, 1979; Lindvall et al., 1983; Skagerberg and Lindvall, 1985; Clemens et al., 2006; Charbit et al., 2009; Koblinger et al., 2014).

A previous study examined whether dopaminergic neurons in the SPF project to the IC in the rat (Moriizumi and Hattori, 1992). In contrast to our results, they did not find $\mathrm{TH}$ immunoreactivity in retrogradely labeled cells in the SPF. It is unclear why that study did not detect $\mathrm{TH}$ immunofluorescence in retrogradely labeled SPF neurons projecting to the IC, but one possibility is that the methods used in our study were more sensitive. Our use of confocal imaging and overlaid images ensured that the observed tracer label and TH staining occurred in the same cells. Additionally, the combination of retrograde and anterograde experiments strengthens our results; both clearly showed that dopaminergic neurons in the SPF project to the IC.
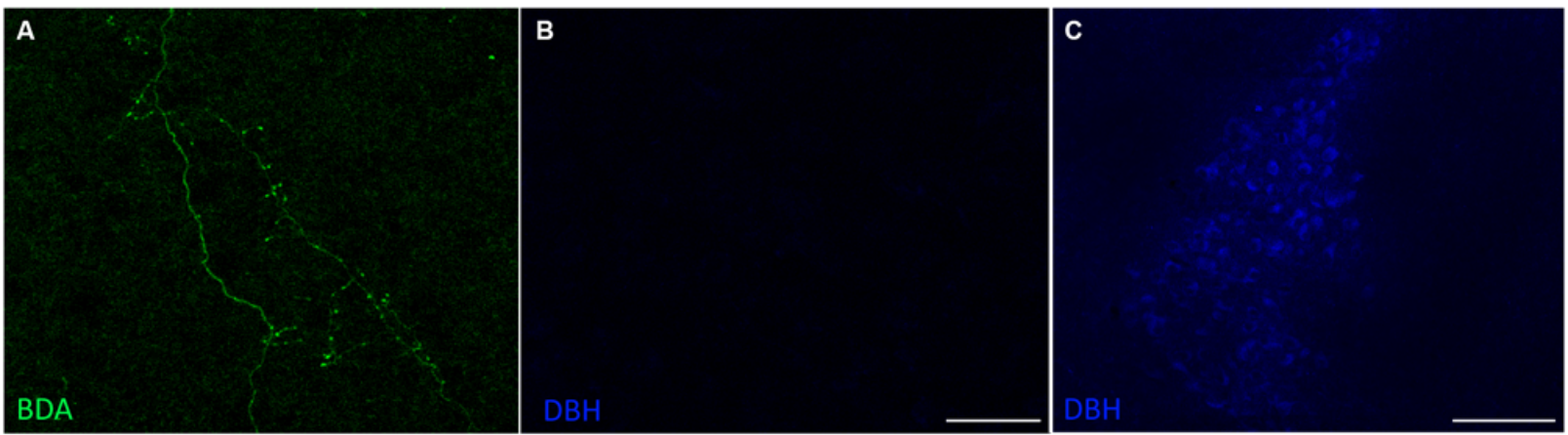

FIGURE 5 | Projections from the SPF to the IC were dopamine beta-hydroxylase (DBH)-negative. (A) Anterogradely labeled fibers and terminals in the $\mathrm{CNIC}$, ipsilateral to the deposit site. (B) Anterogradely labeled fibers and terminals in the CNIC were DBH-negative. (C) DBH-positive cells in the locus coeruleus served as an internal positive control for the DBH antibody. Scale bar: (B) $50 \mu \mathrm{m}$; (C) $100 \mu \mathrm{m}$. 

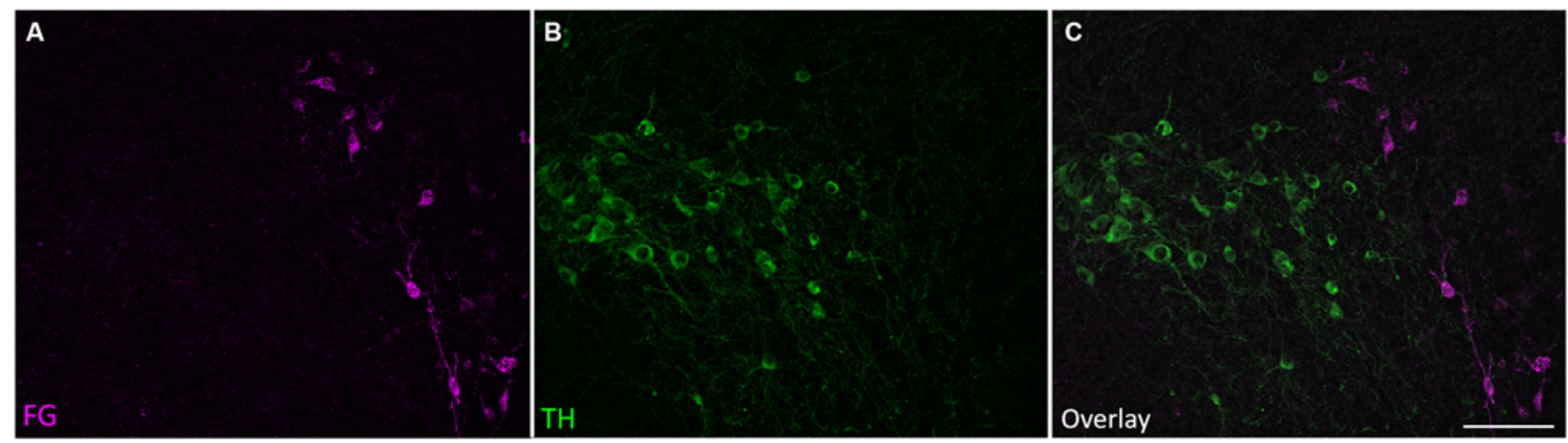

FIGURE 6 | Retrogradely labeled cells outside the SPF were TH-negative. Retrogradely labeled cells in the ipsilateral substantia nigra pars lateralis were TH-negative. (A) Retrogradely labeled cells in the substantia nigra after an IC deposit. (B) TH-positive cells in the substantia nigra. (C) Overlay of images showing that the retrogradely labeled cells in the substantia nigra were not TH-positive. Scale bar $100 \mu \mathrm{m}$.

We are also confident in our tracer deposits because retrogradely labeled cells were found in known auditory structures that project to the IC (Adams, 1979; Brunso-Bechtold et al., 1981; Saldaña et al., 1996; Frisina et al., 1998; Winer et al., 1998), our TH antibody labeled cells in known dopaminergic areas such as the substantia nigra (Hokfelt et al., 1976), and DBHpositive cells were found in the locus coeruleus (Benarroch, 2009).

The SPF is the only nucleus where we found retrogradely labeled, TH-positive, and DBH-negative cells after deposits in the IC. Similar to results of Olazábal and Moore (1989), we found retrogradely labeled cells in the substantia nigra, a known source of dopamine. Although these cells were similar in size and morphology to those that were TH-positive in the substantia nigra and were in close proximity, we did not detect $\mathrm{TH}$ immunoreactivity in them. These cells in the substantia nigra are likely GABAergic (Chevalier et al., 1981; Yasui et al., 1991). Thus, the impairments in processing of emotional cues in speech observed in people with PD (Schröder et al., 2010) are not due to a direct dopaminergic connection from the substantia nigra to the IC. It is possible that the loss of dopamine in the substantia nigra affects auditory processing via a more indirect route that may or may not include the IC. The substantia nigra sends dopaminergic projections to the amygdala (Loughlin and Fallon, 1983), and this may modulate emotional speech processing via the projection from the amygdala to the IC (Marsh et al., 2002).

Yasui et al. (1992) proposed that the SPF may be a central relay nucleus for auditory structures. Not only does the SPF project to the IC, it also projects to the auditory brainstem. It receives input from auditory cortex, auditory thalamus, the superior olivary complex, and from the external and dorsal cortices of IC (LeDoux et al., 1985; Yasui et al., 1990, 1992; Wang et al., 2006). The function of these connections is not yet understood. Neurons of the SPF could release other neurotransmitters besides dopamine, including neuropeptides, allowing a richer repertoire of neuromodulatory signaling. In addition to dopamine, the SPF is known to contain enkephalin, somatostatin, substance $\mathrm{P}$, GABA, and prostaglandins (Wamsley et al., 1980; Graybiel and Elde, 1983; Sugimoto et al., 1984; Kosaka et al., 1987a; Breeder et al., 1995). Currently, it is only known that the SPF sends GABAergic projections to the IC (Moriizumi and Hattori, 1992), although these neurons are not the same neurons as the dopaminergic projections (Kosaka et al., 1987b), and that the SPF sends dopaminergic projections to the IC (this study). Based on these projections, the SPF may play a role in modulating neural responses in the IC, and likely other auditory structures. While it is unknown if the SPF responds to sound, the SPF does show $c$-fos activation after audiogenic stress (Palkovits et al., 2004).

The role dopamine plays in directly modulating neural responses to auditory stimuli has been examined in the IC only by applying exogenous dopamine (Gittelman et al., 2013). The IC contains D2-like dopamine receptors (Wamsley et al., 1989; Weiner et al., 1991) and activating these receptors affects the magnitude and timing of neuronal responses to sounds. Based on the results of the current study, we suggest that the dopaminergic projection from the SPF to the IC plays a role in modulating auditory responses.

The behavioral function of this dopaminergic modulation in auditory functioning is unknown. One possible role may be related to auditory attention. For example, in humans, dopamine is associated with the attentional control of auditory perception (Li et al., 2013). Dopamine may also play a role in the encoding of salience of behaviorally relevant sounds. Because dopamine is involved in attributing salience to reward-related stimuli (Berridge and Robinson, 1998) and neurons in the IC of mice have response properties specific to behaviorally relevant stimuli (Holmstrom et al., 2010), dopamine may differentially alter the encoding of salient sounds in the IC. The role the SPF plays in modulating auditory response properties is a rich avenue for future research.

\section{AUTHOR CONTRIBUTIONS}

All authors had full access to all the data in the study and take responsibility for the integrity of the data and 
the accuracy of the data analysis. Study concept and design: DJP and CVP. Acquisition of data: AAN and CJE. Analysis and interpretation of data: AAN, DJP, and CVP. Drafting of the manuscript: AAN, DJP, and CVP. Obtained funding: DJP and CVP.

\section{REFERENCES}

Adams, J. C. (1979). Ascending projections to the inferior colliculus. J. Comp. Neurol. 183, 519-538. doi: 10.1002/cne.901830305

Benarroch, E. E. (2009). The locus coeruleus norepinephrine system: functional organization and potential clinical significance. Neurology 73, 1699-1704. doi: 10.1212/WNL.0b013e3181c2937c

Berridge, K. C., and Robinson, T. E. (1998). What is the role of dopamine in reward: hedonic impact, reward learning, or incentive salience? Brain Res. Brain Res. Rev. 28, 309-369. doi: 10.1016/s0165-0173(98)00019-8

Blessing, W. W., and Chalmers, J. P. (1979). Direct projection of catecholamine (presumably dopamine)-containing neurons from hypothalamus to spinal cord. Neurosci. Lett. 11, 35-40. doi: 10.1016/0304-3940(79)90052-1

Breeder, C. D., Dewitt, D., and Kraig, R. P. (1995). Characterization of inducible cyclooxygenase in rat brain. J. Comp. Neurol. 355, 296-315. doi: 10.1002/cne. 903550208

Brunso-Bechtold, J. K., Thompson, G. C., and Masterton, R. B. (1981). Hrp study of the organization of auditory afferents ascending to central nucleus of inferior colliculus in cat. J. Comp. Neurol. 197, 705-722. doi: 10.1002/cne.9019 70410

Charbit, A. R., Akerman, S., Holland, P. R., and Goadsby, P. J. (2009). Neurons of the dopaminergic/calcitonin gene-related peptide A11 cell group modulate neuronal firing in the trigeminocervical complex: an electrophysiological and immunohistochemical study. J. Neurosci. 29, 12532-12541. doi: 10. 1523/JNEUROSCI.2887-09.2009

Chevalier, G., Thierry, A. M., Shibazaki, T., and Féger, J. (1981). Evidence for a GABAergic inhibitory nigrotectal pathway in the rat. Neurosci. Lett. 21, 67-70. doi: 10.1016/0304-3940(81)90059-8

Clemens, S., Rye, D., and Hochman, S. (2006). Restless legs syndrome: revisiting the dopamine hypothesis from the spinal cord perspective. Neurology 67, 125-130. doi: 10.1212/01.wnl.0000223316.53428.c9

Forlano, P. M., Kim, S. D., Krzyminska, Z. M., and Sisneros, J. A. (2014). Catecholaminergic connectivity to the inner ear, central auditory and vocal motor circuitry in the plainfin midshipman fish Porichthys notatus. J. Comp. Neurol. 522, 2887-2927. doi: 10.1002/cne.23596

Frisina, R. D., Walton, J. P., Lynch-Armour, M. A., and Byrd, J. D. (1998). Inputs to a physiologically characterized region of the inferior colliculus of the young adult CBA mouse. Hear. Res. 115, 61-81. doi: 10.1016/s0378-5955(97)00176-7

Gittelman, J. X., Perkel, D. J., and Portfors, C. V. (2013). Dopamine modulates auditory responses in the inferior colliculus in a heterogeneous manner. J. Assoc. Res. Otolaryngol. 14, 719-729. doi: 10.1007/s10162-013-0405-0

Gräber, S., Hertrich, I., Daum, I., Spieker, S., and Ackermann, H. (2002). Speech perception deficits in Parkinson's disease: underestimation of time intervals compromises identification of durational phonetic contrasts. Brain Lang. 82, 65-74. doi: 10.1016/s0093-934x(02)00002-0

Graybiel, A. M., and Elde, R. P. (1983). Somatostatin-like immunoreactivity characterizes neurons of the nucleus reticularis thalami in the cat and monkey. J. Neurosci. 3, 1308-1321.

Hokfelt, T., Johansson, O., Fuxe, K., Goldstein, M., and Park, D. (1976). Immunohistochemical studies on the localization and distribution of monoamine neuron systems in the rat brain. I. Tyrosine hydroxylase in the mes- and diencephalon. Med. Biol. 54, 427-453.

Holmstrom, L., Eeuwes, L. B., Roberts, P. D., and Portfors, C. V. (2010). Efficient encoding of vocalizations in the auditory midbrain. J. Neurosci. 30, 802-819. doi: 10.1523/JNEUROSCI.1964-09.2010

Hormigo, S., Horta Júnior Jde, A., Gómez-Nieto, R., and López, D. E. (2012). The selective neurotoxin DSP-4 impairs the noradrenergic projections from the locus coeruleus to the inferior colliculus in rats. Front. Neural Circuits 6:41. doi: $10.3389 /$ fncir.2012.00041

\section{ACKNOWLEDGMENTS}

This work was supported by NIDCD R01DC013102 to CVP and DJP. We thank Jordan M. Blacktop and Phillip M. Uribe for helpful discussions and technical expertise.

Hurd, Y. L., Suzuki, M., and Sedvall, G. C. (2001). D1 and D2 dopamine receptor mRNA expression in whole hemisphere sections of the human brain. J. Chem. Neuroanat. 22, 127-137. doi: 10.1016/s0891-0618(01) 00122-3

Jaeger, C. B., and Joh, T. H. (1983). Transient expression of tyrosine hydroxylase in some neurons of the developing inferior colliculus of the rat. Brain Res. 11, 128-132. doi: 10.1016/0165-3806(83)90208-0

Kitahama, K., Sakamoto, N., Jouvet, A., Nagatsu, I., and Pearson, J. (1996). Dopamine-beta-hydroxylase and tyrosine hydroxylase immunoreactive neurons in the human brainstem. J. Chem. Neuroanat. 10, 137-146. doi: 10. 1016/0891-0618(96)00111-1

Klepper, A., and Herbert, H. (1991). Distribution and origin of noradrenergic and serotonergic fibers in the cochlear nucleus and inferior colliculus of the rat. Brain Res. 557, 190-201. doi: 10.1016/0006-8993(91)90134-h

Koblinger, K., Füzesi, T., Ejdrygiewicz, J., Krajacic, A., Bains, J. S., and Whelan, P. J. (2014). Characterization of A11 neurons projecting to the spinal cord of mice. PLOS One 9:10. doi: 10.1371/journal.pone.0109636

Kosaka, T., Katsumaru, H., Hama, K., Wu, J. Y., and Heizmann, C. W. (1987a). GABAergic neurons containing the $\mathrm{Ca}^{2+}$-binding protein parvalbumin in the rat hippocampus and dentate gyrus. Brain Res. 419, 119-130. doi: 10. 1016/0006-8993(87)90575-0

Kosaka, T., Kosaka, K., Hataguchi, Y., Nagatsu, I., Wu, J. Y., Ottersen, O. P., et al. (1987b). Catecholaminergic neurons containing GABA-like and/or glutamic acid decarboxylase-like immunoreactivities in various brain regions of rat. Exp. Brain Res. 66, 191-210. doi: 10.1007/bf00236215

Kwan, L. C., and Whitehill, T. L. (2011). Perception of speech by individuals with Parkinson's disease: a review. Parkinsons Dis. 2011:389767. doi: 10 4061/2011/389767

Leblois, A., Wendel, B. J., and Perkel, D. J. (2010). Striatal dopamine modulates basal ganglia output and regulates social context-dependent behavioral variability through D1 receptors. J. Neurosci. 30, 5730-5743. doi: 10. 1523/JNEUROSCI.5974-09.2010

LeDoux, J. E., Ruggiero, D. A., and Reis, D. J. (1985). Projections to the subcortical forebrain from anatomically defined regions of the medial geniculate body in the rat. J. Comp. Neurol. 242, 182-213. doi: 10.1002/cne.902420204

Lindvall, O. L., Björklund, A. B. R., and Skagerberg, G. (1983). Dopaminecontaining neurons in the spinal cord: anatomy and some functional aspects. Ann. Neurol. 14, 255-260. doi: 10.1002/ana.410140302

Li, S. C., Passow, S., Nietfeld, W., Schröder, J., Bertram, L., Heekeren, H. R., et al. (2013). Dopamine modulates attentional control of auditory perception: DARPP-32 (PPP1R1B) genotype effects on behavior and cortical evoked potentials. Neuropsychologia 51, 1649-1661. doi: 10.1016/j.neuropsychologia. 2013.04.005

Loughlin, S. E., and Fallon, J. H. (1983). Dopaminergic and non-dopaminergic projections to amygdala from substantia nigra and ventral tegmental area Brain Res. 262, 334-338. doi: 10.1016/0006-8993(83)91029-6

Maia, T., and Frank, M. J. (2011). From reinforcement learning models to psychiatric and neurological disorders. Nat. Neurosci. 14, 154-162. doi: 10 $1038 / \mathrm{nn} .2723$

Marsh, R. A., Fuzessery, Z. M., Grose, C. D., and Wenstrup, J. J. (2002). Projection to the inferior colliculus from the basal nucleus of the amygdala. J. Neurosci. 22, 10449-10460.

Metzger, R. R., Greene, N. T., Porter, K. K., and Groh, J. M. (2006) Effects of reward and behavioral context on neural activity in the primate inferior colliculus. J. Neurosci. 26, 7468-7476. doi: 10.1523/jneurosci.540105.2006

Moriizumi, T., and Hattori, T. (1992). Anatomical and functional compartmentalization of the subparafascicular thalamic nucleus in the rat. Exp. Brain Res. 90, 175-179. doi: 10.1007/bf00229269 
Muniak, M., Ryugo, D. K., Mayko, Z. M., and Portfors, C. V. (2012). An awake mouse preparation for recording neural response properties and injecting tracers. J. Vis. Exp. 64:e3755. doi: 10.3791/3755

Olazábal, U. E., and Moore, J. K. (1989). Nigrotectal projection to the inferior colliculus: horseradish peroxidase transport and tyrosine hydroxylase immunohistochemical studies in rats, cats and bats. J. Comp. Neurol. 282, 98-118. doi: 10.1002/cne.902820108

Palkovits, M., Dobolyi, A., Helfferich, F., and Usdin, T. B. (2004). Localization and chemical characterization of the audiogenic stress pathway. Ann. N Y Acad. Sci. 1018, 16-24. doi: 10.1196/annals. 1296.002

Paloff, A. M., and Usunoff, K. G. (2000). Tyrosine hydroxylase-like immunoreactive synaptic boutons in the inferior colliculus of the cat. Ann. Anat. 182, 423-426. doi: 10.1016/s0940-9602(00)80047-3

Paxinos, G., and Franklin, K. (2001). The Mouse Brain in Stereotaxic Coordinates. 2nd Edn. San Diego, CA: Academic Press.

Portfors, C. V., Mayko, Z. M., Jonson, K. G., Cha, G., and Roberts, P. D. (2011) Spatial organization of receptive fields in the auditory midbrain of awake mouse. Neuroscience 193, 429-439. doi: 10.1016/j.neuroscience.2011.07.025

Saldaña, E., Feliciano, M., and Merchan, M. A. (1996). Distribution of descending projections from primary auditory neocortex to inferior colliculus mimics the topography of intracollicular projections. J. Comp. Neurol. 371, 15-40. doi: 10. 1002/(sici)1096-9861(19960715)371:1<15::aid-cne2>3.0.co;2-o

Satake, S., Yamada, K., Melo, L. L., and Silva, R. B. (2012). Effects of microinjections of apomorphine and haloperidol into the inferior colliculus on prepulse inhibition of the acoustic startle reflex in rat. Neurosci. Lett. 509, 60-63. doi: 10.1016/j.neulet.2011.12.052

Schröder, C., Nikolova, Z. T., and Dengler, R. (2010). Changes of emotional prosody in Parkinson's disease. J. Neurol. Sci. 289, 32-35. doi: 10.1016/j.jns. 2009.08.038

Skagerberg, G., and Lindvall, O. (1985). Organization of diencephalic dopamine neurones projecting to the spinal cord in the rat. Brain Res. 342, 340-351. doi: 10.1016/0006-8993(85)91134-5

Sugimoto, T., Takada, M., Kaneko, T., and Mizuno, N. (1984). Substance Ppositive thalamocaudate neurons in the center median-parafascicular complex in the cat. Brain Res. 323, 181-184. doi: 10.1016/0006-8993(84)90285-3

Takada, M. (1993). Widespread dopaminergic projections of the subparafascicular thalamic nucleus in the rat. Brain Res. Bull. 32, 301-309. doi: 10.1016/03619230(93)90191-d

Takada, M., Li, Z. K., and Hattori, T. (1988). Single thalamic dopaminergic neurons project to both the neocortex and spinal cord. Brain Res. 455, 346-352. doi: 10.1016/0006-8993(88)90093-5
Tong, L., Altschuler, R. A., and Holt, A. G. (2005). Tyrosine hydroxylase in rat auditory midbrain: distribution and changes following deafness. Hear. Res. 206, 28-41. doi: 10.1016/j.heares.2005.03.006

Wamsley, J. K., Gehlert, D. R., Filloux, F. M., and Dawson, T. M. (1989). Comparison of the distribution of D-1 and D-2 dopamine receptors in the rat brain. J. Chem. Neuroanat. 2, 119-137.

Wamsley, J. K., Young, W. S., III, and Kuhar, M. J. (1980). Immunohistochemical localization of enkephalin in rat forebrain. Brain Res. 190, 153-174. doi: 10 1016/0006-8993(80)91166-x

Wang, J., Palkovits, M., Usdin, T. B., and Dobolyi, A. (2006). Afferent connections of the subparafascicular area in rat. Neuroscience 138, 197-220. doi: 10.1016/j. neuroscience.2005.11.010

Weiner, D. M., Levey, A. I., Sunahara, R. K., Niznik, H. B., O’Dowd, B. F., Seeman, P., et al. (1991). D1 and D2 dopamine receptor mRNA in rat brain. Proc. Natl. Acad. Sci. U S A 88, 1859-1863. doi: 10.1073/pnas. 88.5.1859

Winer, J. A., Larue, D. T., Diehl, J. J., and Hefti, B. J. (1998). Auditory cortical projections to the cat inferior colliculus. J. Comp. Neurol. 400, 147-174. doi: 10. 1002/(sici)1096-9861(19981019)400:2<147::aid-cne1>3.3.co;2-v

Yasui, Y., Kayahara, T., Nakano, K., and Mizuno, N. (1990). The subparafascicular thalamic nucleus of the rat receives projection fibers from the inferior colliculus and auditory cortex. Brain Res. 537, 323-327. doi: 10.1016/00068993(90)90378-o

Yasui, Y., Nakano, K., Kayahara, T., and Mizuno, N. (1991). Non-dopaminergic projections from the substantia nigra pars lateral to the inferior colliculus in the rat. Brain Res. 559, 139-144. doi: 10.1016/0006-8993(91) 90296-8

Yasui, Y., Nakano, K., and Mizuno, N. (1992). Descending projections from the subparafascicular thalamic nucleus to the lower brainstem in the rat. Exp. Brain Res. 90, 508-518. doi: 10.1007/bf00230933

Conflict of Interest Statement: The authors declare that the research was conducted in the absence of any commercial or financial relationships that could be construed as a potential conflict of interest.

Copyright (c) 2016 Nevue, Elde, Perkel and Portfors. This is an open-access article distributed under the terms of the Creative Commons Attribution License (CC BY). The use, distribution and reproduction in other forums is permitted, provided the original author(s) or licensor are credited and that the original publication in this journal is cited, in accordance with accepted academic practice. No use, distribution or reproduction is permitted which does not comply with these terms. 